Monatsschrift für Geburtshülfe u. Gynäkologie 1909;30:260

\title{
Gustav Lott †
}

Am 16. d. Mts. verschied zu Wien in seinem 67. Lebensjahre Prof. Dr. Gustav Christian Lott. In ihm verliert die Wiener Allgemeine Poli-klinik den langjährigen Vorstand ihrer stark frequentierten gynäkologischen Abteilung, die Wiener Ärzteschaft einen bewährten Fachmann, die Wiener Gynäkologische Gesellschaft ein hochverdientes Mitglied und mehrjährigen Vorsitzenden. Ganz besonders betrauert man den Verlust einer hoch-achtbaren, liøbenswürdigen Persönlichkeit. ZuWien geboren, hat Lott seine allgemeine medizinische Ausbildung an der Wiener Universität, woselbst er zu jener Schar von Jüngern zählte, die im Brückeschen Laboratorium solide Grundlagen für ihre weitere Tätigkeit sich aneigneten, seine fachliche Ausbildung an der Grazer Frauenklinik unter Hßllys Leitung gewonnen. Dort hat er auch die seiner Zeit viel gelesene und oft zitierte Monographic über die anatomische Beschaffenheit der Cervix uteri verfasst, wobei ihm des Physiologen Rollett Rat sehr zu statten kam. - In seiner Lehr-tätigkeit an der Wiener medizinischen Fakultät folgte er Chrobak nach, dessen stark besuchte gynäkologische Kurse er übernahm. Die letzten Jahre lehrte er ausschliesslich an der Poliklinik.

A. Martin. A. v. Rosthom.

VerantwortUcher Redakteur: A. Martin in Berlin. 